\title{
REPORTES CLINICOS: INFECCION RINOSINUSAL PROBADA POR Aspergillus flavus Y PROBABLE INFECCION PULMONAR POR Emericella nidulans EN PACIENTES INMUNODEPRIMIDOS.
}

\author{
(Clinical reports: tested rhinosinusal infection by Aspergillus flavus and probable \\ pulmonary infection by Emericella nidulans in immunodepressed patients)
}

\author{
*Rodrigo Cruz C., **Elizabeth Barthel M. \\ *Eduardo Piontelli L., ***Gonzalo Fernandez C. \\ *Cátedra de Micología Universidad de Valparaíso, Casilla 92 V. Valparaíso Chile. \\ **Servicio de Medicina Hospital Naval Almirante Nef de Viña del Mar, Chile. \\ ***Servicio de Medicina Hospital de Peñablanca. Villa Alemana, Chile
}

Palabras Clave: Aspergilosis pulmonar, rinosinusal, Emericella nidulans, Aspergillus flavus. Key words: Pulmonar an rhinosinusal aspergillosis, Emericella nidulans, Aspergillus flavus.

\section{RESUMEN}

En los ultimos 20 años la incidencia de aspergilosis invasiva ha aumentado entre 5 y 10 veces, presentando una mortalidad que varía desde un 60 a 98\% dependiendo de su localización, enfermedad de base (inmunodepresión), diagnóstico y tratamiento precoz. A pesar que se ha logrado un importante avance en estos dos últimos decenios, aproximadamente un $50 \%$ de los casos se diagnostican post mortem. Se reportan dos casos de aspergilosis (probada y probable) en pacientes inmunodeprimidos de 21 y 44 años respectivamente. El primer caso corresponde a una infección rinosinusal en una paciente con leucemia linfoblastica, con un cuadro clínico caracterizado por aumento de volumen facial izquierdo, compromiso progresivo del estado general y equímosis en región periorbitaria. La endoscopia nasal detectó abundante secreción y tejido friable amarillento sugerente de infección micótica. Las muestras de tejidos enviadas al laboratorio para exámen directo y cultivos arrojaron presencia de hifas en la mucosa y crecimiento abundante de Aspergillus flavus. Se inició terapia con itraconazol, cambiándose posteriormente a voriconazol, con respuesta favorable y disminución del dolor y volumen facial. Sin embargo, la paciente fallece al $10^{\circ}$ día del ingreso debido a su mal estado general, avance de la falla medular y posterior insuficiencia respiratoria.

El segundo caso corresponde a una probable infección pulmonar en una paciente con cáncer de mama en tratamiento quimioterápico. La paciente ingresó con el diagnóstico de neutropenia febril y probable neumonia de etiología bacteriana, fue tratada con antimicrobianos tanto en el hospital comunal como en el de base. Sin embargo, presentó una evolución tórpida, cursando posteriormente con hemoptisis, insuficiencia respiratoria y compromiso de conciencia. Se tomaron muestras de secreción endotraqueal las que fueron enviadas para estudio bacteriológico(TBC) y micológico, además de hemo y urocultivos. Los resultados de los examenes efectuados fueron negativos, excepto todos los cultivos micológicos que tempranamente (4 días) detectaron un amplio crecimiento de Aspergillus (Emericella) nidulans. Al momento del informe micológico la paciente había fallecido en el hospital base.

\section{ABSTRACT}

In the lately twenty years the incidence of invasive spergillosis has increased five and ten times, causing a mortality rate ranging from 60 to $98 \%$, depending on its location, nature of disease (immunodepression), diagnosis and forward treatment. In spite of the fact that there has been a significant progress in this lately period of twenty years, about $50 \%$ of cases were detected post mortem. Two cases of spergillosis (tested and probable) in 21 and 44 aged immunodepressed patients respectively are herein reported. The first case involves a rhinosinusal infection in a female patient diagnosed with 
lymphoblastic leukemia, whose clinical symptoms were an increase in the left volume of her face, a progressive compromise in her overall state of health and ecchymosis in her periorbitary region. Nasal endoscopy revealed abundant secretion and yellowish friable tissues which suggested a mycotic infection. Samples of tissues sent to the lab for direct exam and cultures revealed the presence of hypha in the mucus and an abundant growth of Aspergillus flavus. The first therapy was with itraconazol, changing later on to voriconazol what resulted in a decrease of pain and face volume. However, the patient dies on the tenth day of her ingress due to her bad state of health, progress in glandular failure and ultimate respiratory insufficiency.

The second case involves a probable pulmonary infection in a patient diagnosed with breast cancer and receiving chemotherapy treatment. She was ingressed with a febrile neutropenia and a probable bacterial etiology pneumonia and she was treated with antimicrobial medication both in the community hospital and in the base building. However, she showed a torpid evolution followed furthermore by hemoptisis, respiratory insufficiency and consciousness compromise. Samples of endotraqueal secretion were taken in order to submit them to bacteriological and mycological (TBC) studies, together with hemo and urocultures. Results of exams were negative except for all mycological cultures which in an early stage (four days) exhibited a high growth of Aspergillus (Emericella) nidulans. Upon the moment of delivering the mycological report, the patient had died in the base hospital.

\section{INTRODUCCION}

Las infecciones fúngicas sistémicas han aumentado en los últimos años y actualmente el concepto de inmunodepresión no se restringe a aquellos pacientes con cáncer, transplantados o portadores del VIH, sino que comprende también a aquellos que pueden presentar una serie de factores de riesgo tales como quimioterapia antineoplasica, neutropénia, tratamiento con corticoides o antimicrobianos de amplio espectro, diabetes, cirugías extensas, procedimientos invasívos, enfermedad pulmonar obstructiva crónica, grandes quemados, enfermedades del colágeno, alcoholismo, hemodiálisis, estancia en UCI, etc. (Pontón, 2003).

En los microhongos oportunistas exógenos, las especies de Aspergillus son mayoritariamente saprofíticas y cosmopolitas, distribuidas principalmente en los nichos ecológicos del suelo donde ejercen un rol esencial en el reciclaje de compuestos carbonados y nitrogenados presentes en la vegetación en descomposición (Pitt, 1994; Haines,1995). La mayoría de las especies esporulan profusamente y sus conidios son liberados abundantemente en la atmósfera, donde permanecen en suspensión en ambientes internos y externos por tiempos prolongados debido a su pequeño tamaño (Samson et al.,2000). En estudios de ambientes hospitalarios, se han cultivado directamente desde el aire, sistemas de ventilación, alimentos, plantas ornamentales, polvo de salas hospitalarias en construcción, alfombras, etc. ( Thompson et al., 1989; Walsh \& Dixon, 1989; Summerbel et al., 1989; Gerson et al; 1994; Heinemann et al., 2004). La alta concentración de estos hongos puede constituir un riesgo de infecciones nosocomiales principalmente en pacientes inmunodeprimidos (Labarca, 2005).

Estudios ambientales han indicado que los humanos pueden inhalar diariamente, acorde al ambiente, varios cientos de conidios de A. fumigatus al día (Goodley et al., 1994; Hospenthal et al., 1998). Sin embargo, su inhalación por individuos inmunocompetentes raramente tienen efectos adversos, debido a que estos propágulos son eficientemente eliminados por la inmunidad celular.

El oportunismo de las especies de Aspergillus pueden causar desde alergias hasta infecciones invasivas y en ambos casos los órganos implicados son los pulmones o las vias aéreas superiores, pero otras localizaciones diversas son conocidas en la literatura (Latge, 1999).

Del total de especies de Aspergillus reconocidas, aproximadamente unas 20 se han detectado como potenciales patógenas del hombre, de estas las más importantes en frecuencia son $\boldsymbol{A}$. fumigatus en primer lugar y le siguen A.flavus, A. niger, A.(Emericella)nidulans y A.terreus (Herbrcht et al., 2002).

La aspergilosis invasiva presenta una elevada mortalidad, la cual varía desde un $60 \%$ hasta el $98 \%$ dependiendo de la localización de la infección, la patología de base y del oportuno diagnóstico y tratamiento. Para su diagnóstico precoz, se cuenta en la actualidad con la serología (test de galactomanano), escaner pulmonar (signo del halo y del aire creciente), además de exámenes como directo, cultivo, biopsias y biología molecular (GarcíaRuíz, 2004).

Los criterios diagnósticos de aspergilosis invasiva se basan en tres conceptos importantes que corresponden a infección probada, probable y posible, los cuales fueron definidos por EORTC (European Organization for Research and Treatment of Cancer) y el Mycoses Study Group del NIAID(National Institute of Allergy and Infectious Diseases)(Pontón, 2003).

1.Infección probada. Presencia histo o citopatológica de hifas tabicadas procedente de aspiración con aguja o biopsia con evidencia (microscópica o por imagen) de daño tisular asociado.- Cultivo positivo de Aspergillus sp. procedente de muestra de localización estéril, existiendo datos clínicos o radiológicos compatibles 
(excluyendo orina y mucosas).

2. In fección probable. Debe cumplirse al menos un criterio de factor de riesgo de hospedador más un criterio microbiológico y un criterio clínico mayor (o dos criterios clínicos menores) compatibles con infección.

3. Infección posible. Debe cumplirse al menos un criterio de factor de hospedador más un criterio microbiológico o un criterio clínico mayor (o dos criterios clinicos menores) compatibles con infección.

\section{CASO CLINICO 1}

Paciente de sexo femenino, de 21 años, con antecedente de leucemia linfoblástica aguda de 5 años de evolución, refractaria a tratamiento y con compromiso del sistema nervioso central, además de antecedente de infección sinusal antigua por hongo del género AspergiIlus no deteminado.

Ingresó el 27 de junio de 2005 al Hospital Naval Almirante Nef de Viña del Mar, por cuadro clínico caracterizado por aumento de volumen facial izquierdo, doloroso, asociado a episodios de desorientación, temblores, compromiso progresivo del estado general y aparición de equímosis en región periorbitaria izquierda y en extremidades.

Al examen físico de ingreso, destacaba la presencia de aumento de volumen, eritema y dolor desde la mejilla izquierda a región submaxilar y cuello, con presencia de ulceraciones en la mucosa oral y aparición de placas blanquecinas friables a nivel faríngeo.

Los estudio de laboratorio destacaban un hematocrito de $19 \%$, recuento de leucocitos de 200 por $\mathrm{mm} 3$ y recuento de plaquetas de 10.000 por $\mathrm{mm} 3$.

Se inició tratamiento antimicrobiano con sulbactamampicilina y clindamicina por probable infección bacteriana de partes blandas, además de manejar el dolor con morfina, ketoprofeno y corticoides. Se solicitó evaluación por infectología, planteándose la posibilidad de infección rinosinusal por hongos Zygomycetes ( Mucorales) o del género Aspergillus. Se realizó endoscopia nasal visualizandose secreción y tejido friable amarillento a nivel de la pared lateral de la fosa nasal izquierda, sugerente de infección micótica, por lo que se tomaron muestras de ese tejido. Cursó con epistaxis post-procedimiento, requiriendo taponamiento nasal anterior, el cual fue retirado a las 24 horas sin incidentes.

Las muestras del tejido fueron enviadas al laboratorio de micología, lugar donde se realizó exámen directo y siembras en agar Sabouraud a $37^{\circ} \mathrm{C}$. En el exámen directo por maceración del tejido se observaron abundates hifas hialinas septadas y a partir del segundo día se observó en todas las siembras un abundante crecimiento de un hongo filamentoso del genero Aspergillus, deter- minándose posteriormente como $\boldsymbol{A}$. flavus Link.

Se inició terapia con itraconazol vo, cambiándose luego por voriconazol en dosis de $6 \mathrm{mg} / \mathrm{kg}$ cada 12 horas el primer día y luego $4 \mathrm{mg} / \mathrm{kg}$ cada 12 horas, respondiendo con disminución del dolor y del aumento de volumen facial. Sin embargo, la paciente fallece al $10^{\circ}$ día del ingreso por avance de la falla medular e insuficiencia respiratoria

Aspectos morfológicos. Los estudios morfológicos se basaron en la selección de 3 aislamientos, cultivándose en medios especiales AM, CYA y CYA20S según el manual de identificación de Klich (2002).

Los diámetro de las colonias en CYA a $25^{\circ} \mathrm{C}$ a $\operatorname{los} 7$ dias de cultivo fueron de 58-64mm, en MEA a la misma temperatura $(60-66 \mathrm{~mm})$ y en $\mathrm{CYAa} 37^{\circ} \mathrm{C}(53-62 \mathrm{~mm})$. Textura y colores acorde a las descripciones.

Las características microscópicas (Figura 1) fueron: cabezas típicamente radiadas a columnares laxas con conidióforos rugosos, hialinos, largos $(650 \mu \mathrm{m}$ en promedio) y con un ancho entre $9-13 \mu \mathrm{m}$; vésiculas esféricas, $22-38 \mu \mathrm{m}$ de ancho y con un $50-60 \%$ de ellas biseriadas; métulas de 9-12 x 5-7 $\mu \mathrm{m}$. Fiálides comprimidas sobre las métulas, $8-10 \times 3-4 \mu \mathrm{m}$ y conidios globosos a elipsoidales, lisos a finamente rugosos, 3-4,5 $\mu \mathrm{m}$.

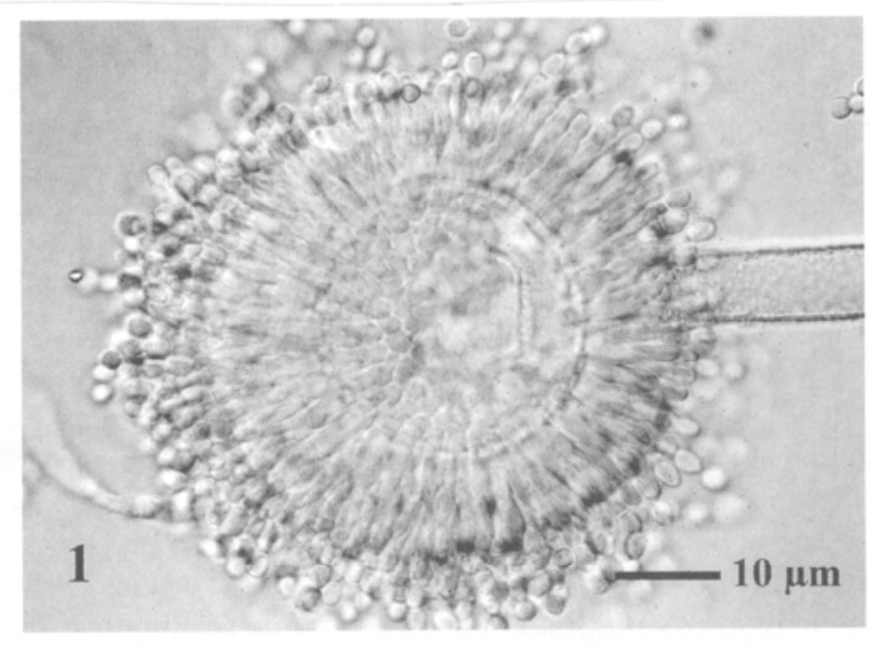

Figura 1.- Aspegillus flavus (DIC)

\section{CASO CLINICO 2}

Paciente femenino de 44 años de edad, con antecedentes de cáncer de mama derecha operada el día 18 noviembre del 2004 y quimioterapia realizada los días $26 / 01 / 05$ y $22 / 02 / 05$, primer y segundo ciclo respectivamente.

Desde el día 04/03/05 presenta cuadro clínico caracterizado por fiebre de $40^{\circ} \mathrm{C}$, tos con expectoración 


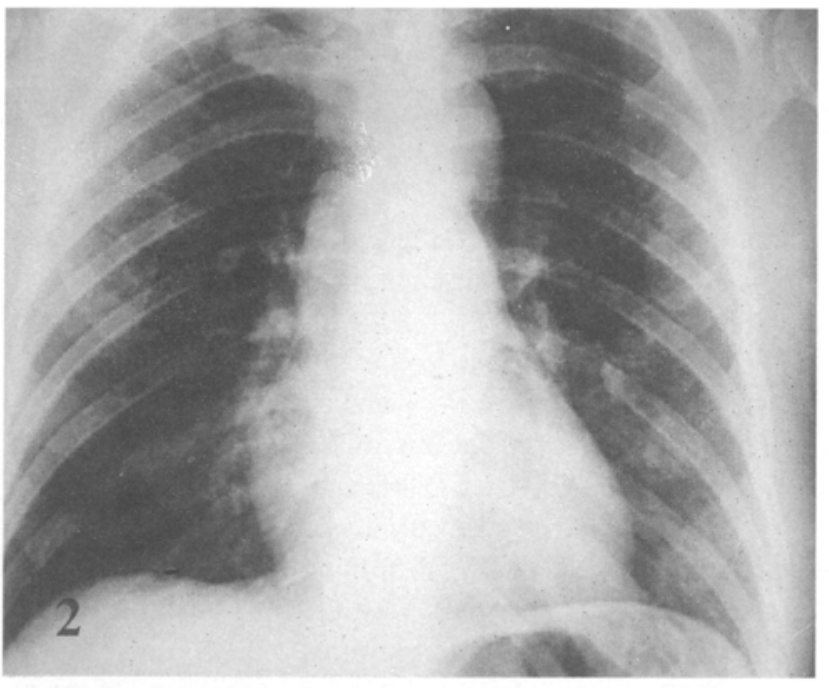

Figura 2.- Radiografía de puimón anteroposterior

purulenta, calofríos, vómitos a repetición y diarrea escasa. Consulta con médico particular quién la envía a la unidad de emergencia del hospital de Peñablanca (10/03/05). En este recinto se constata deshidratación moderada, $\mathrm{P} / \mathrm{A}$ de $130 / 70$, fiebre de $38,5^{\circ} \mathrm{C}$ y frecuencia respiratoria de 25 por minuto, además de candidosis orofaringea y onicomicósis de manos y pies. Se decide hospitalizarla con el diagnóstico de síndrome febril en estudio, probable sepsis de origen pulmonar y cáncer de mama en quimioterapia. Dentro de los exámenes destacó un recuento de leucocitos de 1700 células $/ \mathrm{m}^{3}$, con un recuento absoluto de neutrófilos de 935 células $/ \mathrm{m}^{3} \mathrm{y}$ radiografía de tórax con un infiltrado intersticial difuso en ambos campos pulmonares (Figura. 2 ), además de una VHS de 30 , hematocrito de $24.5 \%$, recuento de plaquetas de $154 \mathrm{mil} / \mathrm{m} 3$, pruebas hepáticas normales y creatininemia de 0.4 . También se tomaron hemocultivos, urocultivo, coprocultivo, baciloscopias de expectoración y cultivo Lowenstein-Jensen. A las 48 horas de su ingreso empeora su condición general y persiste la fiebre, razón por la cual 'se decide traslado a Hospital de mayor complejidad. En este recinto se diagnostica neumonia de la comunidad ATS III, por lo que se sugiere nuevamente manejo en el hospital de Peñablanca, iniciandose allí tratamiento antibiótico con cefotaxíma $1 \mathrm{gr}$ c/ 8 hrs más amikacina 1 gr/día endovenosa, además de aporte de volumen ev, nebulizaciónes con salbutamol y apoyo kinésico respiratorio.

El día 14/03/05 la paciente se mantiene febril pero estable hemodinamicamente, con baciloscopias negativas, urocultivo y hemocultivos negativos, por lo que el médico tratante considerando su estado general y la persistencia de la fiebre decide nuevamente trasladar a la paciente al hospital base, lugar donde luego de 8 días de tratamiento ATB ev es dada de alta (23/03/05) con los diagnósticos de
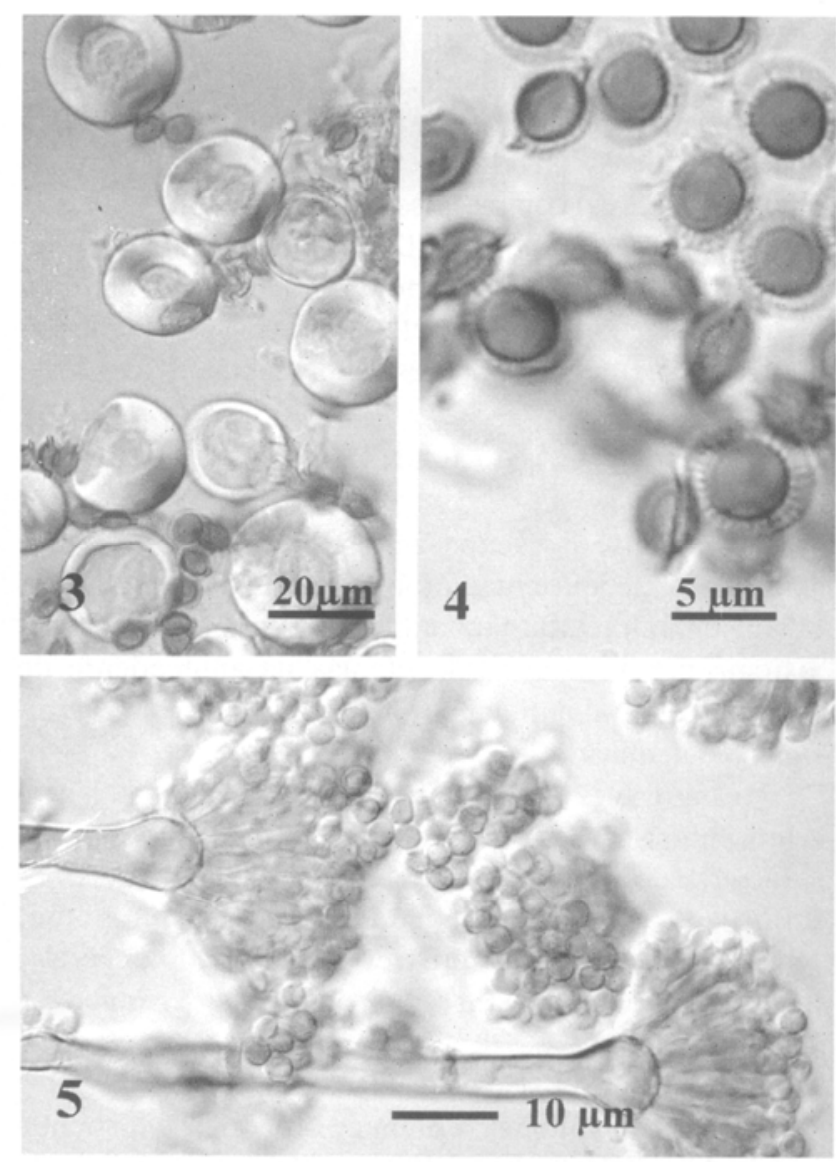

Figuras 3-4-5 Emericella nidulans. - 3. Células Hülle, 4. Ascosporas, 5. Conidióforos y conidios.

neutropénia febril, cáncer de mama en quimioterapia, micosis oral e hipokalémia recuperada. Las indicaciones al alta fueron: cefixima $400 \mathrm{mg}$ día vo, ketoconazol $200 \mathrm{mg}$ vo día y ácido fólico.

El día 28/03/05 es llevada por familiares a la UE del hospital de Peñablanca por presentar compromiso de conciencia, fiebre de 40 grados, frecuencia respiratoria de 30 por minuto, frecuencia cardiaca de 140 por minuto, $\mathrm{P} / \mathrm{A}$ : $100 / 60$, estertores pulmonares difusos, disnea y hemoptisis. Se realiza intubación orotraqueal, se administra oxígeno, suero fisiológico 2000cc y se toman muestras endotraqueales de secreción para cultivo bacteriológico, baciloscopias y cultivo de hongos, además de hemo y urocultivo. Posteriormente cursa con paro cardiorespiratorio, se realizan maniobras de resucitación con buena respuesta por lo que se traslada al hospital base, lugar donde muere luego de unas horas de manejo.

Las muestras de secreción endotraqueal fueron enviadas el mismo día al laboratorio de micología, donde fueron sembradas en tres tubos de agar Sabouraud a $37^{\circ} \mathrm{C}$. Al cuarto día se observó abundante crecimiento en todos los tubos de un hongo filamentoso del género Aspergillus, 
que los 7 días de incubación presentó presencia de cleistotecios, clasificándose con el nombre de su teleomorfo Emericella nidulans (Eidam) Vuill. (anamorfo: Aspergillus nidulans, subgénero Nidulantes, seccion Nidulantes de Aspergillus). Los hemocultivos resultaron negativos, al igual que el urocultivo, baciloscopias y cultivo Lowenstein-jensen.

Aspectos morfológicos. Los estudios morfológicos se fectuaron con los mismos procedimientos y medios empleados en el caso anterior, mediante la selección de 3 aislamientos seleccionados al azar para su estudio.

Los diámetro de las colonias en CYA a $25^{\circ} \mathrm{C}$ a en 7 días de cultivo fueron de 47-57 mm, en MEA a la misma temperatura (51-60 $\mathrm{mm}$ ) y en CYAa $37^{\circ} \mathrm{C}(50-63 \mathrm{~mm})$. Textura y colores acorde a las descripciones

Las características microscópicas los 7 días en AM del anamorfo(Figura 5)fueron: cabezas conidiales columnares de tonos de color verde amarillentos, conidióforos cortos (45-100x 3-5,5 $\mu \mathrm{m}$ ), lisos, de color café en el tiempo, con vesículas globosas a piriforme estrictamente biseriadas con métulas (4,5-6,5 x 2-3 $\mu \mathrm{m}$ ) y fuálides (5-7 x 2$3 \mu \mathrm{m}$ ) recubriendo sólo la mitad superior de la vesícula, conidios globosos, 3-3,5 $\mu \mathrm{m}$ finamente rugosos

A los 14 días ascomata (cleistotecios) abundantes, globosos, (110-200 $\mu \mathrm{m})$ solitarios, rodeados por una capa de color amarillento a canela de células Hülle globosas a

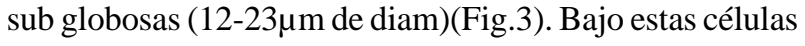
se visualizó la pared del cleistotecio como una sola capa de células parenquimatosas. Ascos globosos a subglobosos $(9-12 \mu \mathrm{m})$ y ascosporas lenticulares en vista lateral, de color rojo púrpura, de paredes lisas y con 2 crestas ecuatoriales sobresalientes (3-4,5 x 3-3,5 $\mu \mathrm{m})$ (Figura. 4).

\section{DISCUSION}

Las especies de Aspergillus, tanto en pacientes inmunocompetentes como en inmunocomprometidos pueden producir a nivel de vías aéreas superiores y pulmón, enfermedaes no ivasivas como las broncopulmonares alérgicas, la colonización de cavidades formadas (aspergiloma) y el impacto mucoide, entre otras (Bennet, 1995), pero la que destaca por su gravedad es la aspergillosis invasiva (Usseti et al, 2000). En este último caso los cuadros clínicos más frecuentes corresponden a rinosinusitis y neumonía necrotizante, pudiendo diseminarse posteriormente a otros órganos (García-Ruíz, 2004). Las imágenes radiologícas son variables y difíciles de diferenciar en su etiología, razón por la cual es urgente la evaluación con escanner pulmonar, test de galacto manano para el diagnóstico precoz de la aspergillosis, pieza crucial en el tratamiento y la sobrevida del paciente.
El cuadro clínico de una aspergilosis pulmonar es inespecífico y puede confundirse con una neumonía bacteriana o viral, razón por la cual se deben considerar aquellos pacientes que presentan factores de riesgo, principalmente neutropenia, transplantes o enfermedades granulomatosas crónicas (Arteaga \& Grande, 1999).

La adquisición del agente fúngico oportunista exógeno no es de fácil resolución en la mayoría de los tipos de aspergilosis y guarda relacion a su presencia ya sea en ambientes externos o internos. Algunos pacientes internados en un hospital pueden haberse colonizado previamente en ambientes asociados a sus actividades diarias, pero en el ambito hospitalario las fuentes principales son de orígen externa (Aira et al, 2005) y los conidios una vez infiltrados se concentran en los ambientes confinados (Rhame, 1991). En un gran hospital de Austria se observó que los rangos de contaminación de sus pasillos no diferían mayormente de los de sus salas de cuidados intensivos, siendo ambos influenciados por las actividades humanas intrahospitalarias (Raine et al., 2001). Ante estas situaciones y aunque los niveles de contaminación en los ambientes internos pueden ser bajos, deben considerarse suficientemente riesgosos para los pacientes con compromiso inmune o transplantados bajo altas dosis de quimioterapéuticos y con neutropenia asociada, los cuales pueden desarrollar cuadros micóticos invasivos nosocomiales. La relación entre la presencia fúngica en el ambiente y la aspergilosis nosocomial resalta la importancia de la vigilancia ambiental y la estrica aplicación de medidas preventivas (Tales como aislamiento en sala con presión positiva dotadas de filtros HEPA(Segal et al., 1998; Nolard \& Heinemann, 2000; Sanchez, 2000).

Emericella(Aspergillus) nidulans, es un raro patógeno en aquellos pacientes con defectos cualitativos o cuantitativos en sus neutrófilos, generalmente es A.fumigatus el patógeno más común en estas poblaciones, sin embargo, $\boldsymbol{A}$. nidulans es más virulento y de mayor mortalidad si se compara con el primero, debido a su gran capacidad de comprometer los huesos adyacentes y causar enfermedad diseminada (Segal et al., 1998, Dotis \& Roilides, 2004). Los aspergilos no A.fumigatus, como A.nidulans, A.niger, A.flavus y A.terreus, son generalmente más resistentes a los fagocitos mononucleares y polimorfonucleares que $\boldsymbol{A}$. fumigatus: este hallazgo debe considerarse durante el manejo de una aspergilosis invasiva causada por estas especies (Akpogheneta et al., 2003).

Nuestra casuística nacional referente a los cuadros clínicos de Aspergilosis broncopulmonar se inicia en la mitad del siglo pasado, evolucionando desde los aportes del diagnóstico basado puramente en hallazgos microbiológicos o histológicos (estos últimos generalmente post mortem) a los primeros intentos de detección de anticuer- 
pos específicos anti Aspergillus en el suero de los enfermos (Yarzabal et al., 1974, Sepulveda et al., 1978, Retamal et al,, 1989). Los aspectos de diagnóstico clínico, anatomopatológicos y de laboratorio se resaltan en: Oddo \& González (1984), Mendoza et al.(1985),Thompson et al. (1985,1987), Oddo \& Thompson (1990), hasta las técnicas de diagnótico más modernas (Guzmán, 2004).

En el caso clinico de probable aspergilosis pulmonar descrito, no se sospechó precozmente una micosis, a pesar de los factores de riesgo que presentaba esta paciente, lo cual impidió un diágnostico y tratamiento oportuno. La evolución tórpida aún con tratamiento antimicrobiano de amplio espectro y la ausencia de cultivos bacterianos positivos sumado al informe micológico, nos hace sospechar una probable aspergilosis pulmonar; sin embargo, la falta de una autopsia (rechazo familiar), impidió corroborar el diagnóstico planteado.

Las infecciones de los senos paranasales pueden agruparse en 4 grupos: a) Las formas invasivas como la sinusitis aguda invasiva (fulminante) y la sinusitis crónica (indolente) y b) Las formas no invasivas como el micetoma y la sinusitis fúngica alérgica. Cualquiera de estas formas puede progresar o estar asociadas con enfermedades más agresivas (Rowe-Jones \&Moore-Guillon,1994; Karci et al., 2001).

La casuistica nacional es escasa ( Cantarutti \& Schurmann 1969; Stott \& Sepulveda,1996) y muy espaciada en el tiempo, seguramente debido a que muchos de los hallazgos no originaron publicaciones posteriores. Los casos más registrados se deben a otros agentes invasores de los senos nasales o paranasales, principalmente Zigomicosis rinocerebral (Bravo et al., 1999; Pruzzo et al., 2000; Wicki et al., 2004; Chavez \& Rahal, 2004). La literatura internacional es muy abundante especialmente en pacientes inmunodeficientes, con cancer o SIDA (Teh, et al.,1995; Johnson et al, 1999; Guillen et al., 2000; Karci et al., 2001), pero tambien se han obsevados en los inmunocompetentes (Tierney et al., 1996; Horre et al, 2002). El agente más común en este cuadro clínico es mayoritariamente $\boldsymbol{A}$.fumigatus pero otras especies se han detectado como A.flavus y A.niger (Teh et al., 1995; Johnson et al, 1999) a pesar que en muchos casos sólo se llega al diagnóstico histológico de Aspergillus (Chen\& Chen, 2000; Guillen et al., 2000).

A.flavus, es un integrante de la sección Flavi del género, de distribución cosmopolita, frecuente en suelos, nueces, especias, semillas oleaginosas, cereales (en especial maíz) y en granos almacenados. Produce varios tipos de metabolitos secundarios considerados tóxicos tales como ac. cojico, ac.3 nitropropiónico, ac. ciclopiazónico, ac. aspergílico y aflatoxina B, en especial esta última, un derivado de las cumarinas que tiene fuerte propiedades carcinogénicas en animales y humanos
(Samson et al., 2000).

El caso clínico descrito de aspergilosis rinosinusal ocurrió en una paciente portadora de una leucemia avanzada con pronóstico ominoso, razón por la cual no se solicitaron otros examenes, salvo la rinoscopía, la cual permitió una acertada sospecha clínica y la muestra de tejido friable para un exámen directo y cultivo micológico, que corroboraron el diágnóstico.

\section{REFERENCIAS}

Akpogheneta, O.; Gil-Lamaignere, C.; Maloukou, A.; Roilides, E. (2003). Antifungal activity of human polimorphonuclear and mononuclear phagocytes against non-fumigatus Aspergillus species. Mycoses 46:77-83

Aira, M. J.; Jato, V.; Iglesias, I.; Rodriguez, F.J.; Méndez, J.; Albelda, Y.; Hervés, M.; Piontelli, E.; Stchigel, A.M. (2005). Calidad del Aire. Polen y esporas en la comunidad gallega. Xunta de Galicia.

Arteaga, E. \&Grande Argudo Elida. (1999). Aspergillosis pulmonar invasora en el síndrome de inmunodeficiencia adquirida. Rev.Iberoameam.Micol. 16:211-215

Benet. J.E. (1995). Aspergillus species. In; Mandel, G.L.;Douglas, R.G. \& Bennet, J.E. (Eds.). Principle and practice of infectious diseases. N.Y.,Churchill livingstone pp.2306-2311

Bravo, M.; Ferrer, S., Ritchard, M.\& Trijillo, S. (1999). Mucormicosis rinocerebral. Comunicaciones de 4 casos. Rev. Méd. Chile. 127:712-718

Cantarutti, R. \& Schurmann, R. (1969). Aspergilosis de las fosas nasales y senos accesorios con compromiso de la meninge basal. Rev. Otorrinolaring. 29:45-47

Chávez, P.A.\& Rahal, E.M. (2004). Mucormicosis rinocerebral en un niño diabético. Tratamiento conservador. Rev. Chil. Infect. 21: $57-60$

Chen, I. \& Chen, T. (2000) Isolated frontal sinus aspergillosis. Otolaryngology- Head and Neck Surgery. 122:460-461

Dotis, J. \& Roilides, E. (2004). Osteomyelitis due to Aspergillus spp. in patients with chronic granulomatous disease: comparison of Aspergillus nidulans and A. fumigatus. Int. J. Infect. Dis. 8:103110

García-Ruiz, J.; Amutio, E.; Pontón, J. (2004). Infección fúngica invasora en pacientes inmunodeficientes. Rev Iberoam Micol; 21:55-62

Gerson, S.L.; Parker, P.; Jacobs, M.R.; Creger, M.; Lazarus, H.M. (1994) Aspergillosis due to carpet contamination. Infect.Control.Hosp. Epidemiol. 15:221-223

Goodley, J.M.; Clayton, Y.M. \& Hay, R.J. (1994). Environmental sampling for aspergilli during building construction on a hospital site. J Hosp Infect.26:27-35

Guillen G,V.F..; Aguirre, G..A.F.; Muñoz,H.A.; Santacruz, R.S.; Blanco, P.P.; Perez, L.C.; Sancipriano, H.A. (2000). Maxilary sinusitis by Aspergillus. An. Otorrinolaringol. Ibero. Am. 27;67-75 
Guzmán, D,A.M.(2005). Importancia del laboratorio en el diagnóstico de las micosis invasoras. Rev. Chil. Infect. 21:39-47

Haines .J. (1995). Aspergillus in compost: straw man or fatal flaw. Biocycle. 6:32-35.

Heinemann,S.; Symoens, F.; Gordts, B.; Jannes, H.; Nolard, N. (2004). Environmental investigations and molecular typing of Aspergillus flavus during an outbreak of postoperative infections. J. Hosp. Inf. 57:149-155

Herbrecht, R.; Denning, D.W.; Patterson, T.F.; Bennett, J.E.; Greene, R.E.; Ostermann, J.M. (2002).. Voriconazol versus Anphoptericin B for primary of invasive Aspergillosis. New Eng. J.Med. 347:408-4

Horre, R.; Scumacher, G.; Marklein, G.; Kromer, B.; Wardelman, E.; Giges, S.; De Hoog, G.S.; Wahl, G.; ScHaal, K.P. (2002). Case report. Maxilary sinus infection due to Emericella nidulans. Mycoses 45:402-405

Hospenthal ,D.R.; Kwon-Chung, K.J. \& Bennett, J.E. (1998). Concentrations of airborne Aspergillus compared to the incidence of invasive aspergillosis: lack of correlation. Med Mycol.;36:165168

Johnson, T.E. Casiano, R.R.; Kronish, J.E.; Tse, D.T.; Meldrum, M.; Chang,W. (1999). Sino-orbital aspergillosis in acquired inmunodeficiency syndrome. Arch.Ophthalmol. 117: 57-64

Karci, B.; Burhanoglu, D.; Hilmioglu, S.; Inci, R.; Veral. A. (2001). Fungal infection of the paranasal sinuses. Rev. Laryngol. Otol. Rhinol. 122:31-35

Labarca J.(2005). Infecciones nosocomiales en pacientes neutropenicos. Magíster en infecciones y epidemiologia hospitalaria. U. de Valparaíso. 2005. pp 1-10

Latge, J.P.(1999). Aspergillus fumigatus and Aspergillosis. Clin. Microbiol. Rev.12:310-350

Mendoza,F.; Retamal,C.; Ferrada, L.; Alvarez de Oro, R.; Pivet,H.; Salamanca. L. (1985). Aspergilosis humana en Chile: Estudio del último decenio. Farmacias 17 (2):8-11:

Nolard, N.\& Heineman, S. (2000). Environmental sampling in the hospital, when, how and were?. Rev. Iberoam. Micol. 17:S112

Oddo, D \& Gonzalez,S (1984). Aspergilosis pulmonar. Estudio morfológico de 15 casos de autopsias. Rev. Med. de Chile 112:247251

Oddo, D. Thompson, L.(1990). Micosis pulmonares. Algunos aspectos de su diagnóstico anatomopatológico y de laboratorio (I). Rev. Chilena Infect. 7:197-207

Pitt ,J.I. (1994). The current role of Aspergillus and Penicillium in human and animal health. J Med Vet Mycol.;S1:17-32.

Pontón, J. ( 2003). Aspergillosis invasora. Primera edición. Asociación Española de Micología.

Pruzzo,Ch.E.; Labarca, L.J.;Guzmán, A.M.; Leon, C.P.;Emmerich, H.M.; Bustos, P. L. Rico,P,B (2000). Rinosinusitis por Pseudallescheria boydii. Rev. Otorinolaring. Cir. Cabeza Cuello 60:109-116

Raine,J.; Peintner,U. \& Poder, R. (2001). Biodiversity and concentration of airborne fungi in a hospital environment. Mycopathologia 149:87-97

Retamal, C.; Oddo, D.; Thompson,L. \& Ferrada, L. (1989).
Aspectos sobre el diagnóstico inmunológico de algunas micosis oportunistas. Rev. Chilena. Infect. 6:7-11

Rhame, F.S. (1991). Prevention of nosocomial aspergillosis. J.Hosp. Infec. 18(suppl. A):466-472

Rowe-Jones, J.M. \& Moore-Gillon, V. (1994). Destructive non invasive paranasal sinus: component of a spectrum of disease. $\mathrm{J}$. Otolaryngol. 23:92-96

Sanchez, J. (2000). Prevención de la aspergilosis nosocomial. Rev. Iberoam. Micol. 17:S100-102

Samson, RA.; Hoekstra, E.S.; Frisvald, J.C.\& Filtenborg, O. (2000) Introduction to food and airborne fungi. $6^{\text {th }}$ ed. Centraalbureau voor Schimmelcultures, The Netherlands

Segal, B.H.; DeCarlo, E.S.; Kwon-Chung, K.J.; Malech, H.L.; Gallin ;J.I.; Holland, S.M. (1998). Aspergillus nidulans infection in chronic granulomatous disease. Medicine (Baltimore) 77:345354

Sepulveda, R.;Longbottom,J.\& Pepys, J. (1978). The uptake of A.fumigatus protein by serum IgG from patient with pulmonary aspergilosis. Clin.Allergy 7:117-125

Stott,C.\& Sepúlveda, J. (1996). Aspergilosis sinusal. Rev. Otorrinolaring. Cir. Cabeza Cuello 56:135-142

Summerbell, R.; Krajden, S. \& Kane,J. (1989). Potted plants in hospitals as reservoirs of pathogenic fungi. Mycopathologia 106:13-22

Teh, W.; Matti, B.S.; Marisiddaiah, H.\& Minamoto, G.Y. (1995). Aspergillus sinusitis in patient with AIDS:report of three cases and review. Clinical Infectious Diseases 21:529-535

Tierney, P.; Thomas, M.; Samuel, D.; Patel, K.; Stafford, N. (1996). Recurrent aspergilloma of the frontoethmoid sinus in a non-immunocompromised patient. J.Royal Soc.Med. 89:165-166

Thompson, L.; Cinte, G.; Carvajal, L.C.; Oddo, D.; Paredes, P. (1985). Aspergilosis pulmonar invasiva en pacientes con leucemia linfoblástica aguda. Rev. Méd. Chile 113:345-351

Thompson, L.; Oddo,D. \& Retamal, C. (1987). Orientaciones clínicas y de laboratorio en micosis oportunistas (I). Rev. Chilena Infect. 4:69-74

Thompson, L.; Delgado, M.; García, M.; Durán, J. (1989). Aislamiento de diversas especies del género Aspergillus de la tierra de plantas ornamentales de interior en el área intrahospitalaria. Libro de resuúmenes IV Congreso Panamericano de Infectología. Caracas.pp. $1 \mathrm{n}^{\circ} 25$

Usseti,P.; De Pablo, A. \& Cruz, A.(2000). Aspergilosis pulmonar. En: Rello, J \& Gallego, M (Eds.) .IMplicaciones terapéuticas de la neumonia nosocomial grave. Barcelona,EDIKA MED. pp.97-108

Walsh, T.J.\& Dixon, D.N. (1989). Nosocomial aspergillosis: environmental microbiology, hospital epidemiology, diagnosis and treatment. Eur. J. Epidemiology 5:1616-1622

Wiki, M.A.; Borel, A.C.; Villaroel, C.M. \& Cofré, G.J. (2004). Curacion de Mucormicosis rinocerebral en un paciente pediátrico con leucemia activa. Rev. Chil. Infect. 21:48-52

Yarzabal,L.; Sepúlveda, R.; Retamal, C.; Kinzel, R.; Castro, M.; Salamanca, L.(1974). Aspergilosis respiratoria humana. Rev. Médica de Chile 102:772-778 